\title{
Single Crystal Castability and Undercoolability of PWA1483 Superalloy
}

\author{
De-Xin $\mathrm{Ma}^{1,2} \cdot$ Fu Wang $^{3} \cdot$ Jian-Zheng Guo ${ }^{1,2} \cdot$ Wen-Liang Xu ${ }^{3}$ \\ Received: 28 October 2018 / Revised: 29 November 2018 / Published online: 6 April 2019 \\ (c) The Chinese Society for Metals (CSM) and Springer-Verlag GmbH Germany, part of Springer Nature 2019
}

\begin{abstract}
Both of the single crystal (SX) castability and undercoolability of PWA1383 superalloy were investigated during the directional solidification and isothermal cooling. In all the six SX parts of a casting cluster, no stray grains were found, revealing a defect-free SX structure. This excellent SX castability of the superalloy was attributed to its good undercoolability. The melting point $\left(T_{\mathrm{L}}\right)$ and the critical nucleation temperature $\left(T_{\mathrm{N}}\right)$ of the alloy were measured to be $1327{ }^{\circ} \mathrm{C}$ and $1306^{\circ} \mathrm{C}$, respectively. The statistic average of the critical nucleation undercooling $\Delta T_{\mathrm{N}}=T_{\mathrm{L}}-T_{\mathrm{N}}$ of the alloy was determined to be about $21 \mathrm{~K}$, exhibiting a relatively great capacity to be deeply cooled to a temperature below the melting point without the onset of solidification.
\end{abstract}

Keywords Superalloys $\cdot$ Crystal growth $\cdot$ Phase transitions

\section{Introduction}

The superalloy blades with single crystal (SX) structure demonstrate superior mechanical performance at elevated temperature, due to the complete elimination of the grain boundaries $[1,2]$. During the solidification of SX blades, the most critical issue is to ensure the integrity of the SX structure and to avoid the formation of stray grains (SGs) [3]. SGs are characterized by the formation of one or more new grains with completely different crystallographic orientations during the directional solidification of the SX casting, resulting in grain boundaries with various angles, which damage the integrity of SC structure [4]. The SGs are unacceptable since they severely degenerate the high temperature performance of the blades, especially for those fabricated with SX superalloys containing no grain boundary strengthening elements. To understand the formation of

Available online at http://link.springer.com/journal/40195

Fu Wang

fuwang@mail.xjtu.edu.cn

1 Wedge Central South Research Institute, Shenzhen 518045, China

2 State Key Laboratory for Powder Metallurgy, Central South University, Changsha 410083, China

3 State Key Laboratory for Manufacturing System Engineering, School of Mechanical Engineering, Xi' an Jiaotong University, Xi' an 710049, China such defect, various investigations have been carried out. Zhang et al. [5] found that the dimension of the platform has strong effects on the tendency of the SG formation. Meng et al. [6] reported that the thermal condition in the platform region is complex, and developed assistant bars technique to inhibit these SGs. In addition, the application of a high magnetic field to suppress the SG formation in the crosssectional change region was proposed by Xuan et al. [7, 8]. By conducting these investigations, the forming mechanism of the stray grain was partly revealed. It was found that SGs are more likely to occur in the enlargement section region of SX blades or vanes, such as the platform, since the temperature of the alloy melt in these areas can be quickly cooled to a temperature lower than the liquidus due to the better heat dissipation, and then, the melt in those regions becomes undercooled. If the undercooling exceeds the undercoolability (critical undercooling for nucleation) of the superalloys, the stray gain forms. Based on the formation mechanism, Meyer ter Vehn et al. [9] and Ma and Bührig-Polaczek [10, 11] developed the grain continuator and the heat conductor techniques, respectively, which can effectively reduce the stray grain formation. In our previous study [12], we found that the composition of superalloys has influence on the stray grain formation within the platforms because of the resulted different undercoolability. Therefore, the formation of the stray grain is also closely related to the undercoolability of superalloys besides the geometry factor of castings [5, 6] and the directional solidification processing parameters $[4,13]$. 
Table 1 Nominal composition of PWA1483 superalloy (wt\%)

\begin{tabular}{lllllllllll}
\hline $\mathrm{Ni}$ & $\mathrm{Al}$ & $\mathrm{Ti}$ & $\mathrm{Cr}$ & $\mathrm{Mo}$ & $\mathrm{Co}$ & $\mathrm{W}$ & $\mathrm{Ta}$ & $\mathrm{Hf}$ & $\mathrm{C}$ & $\mathrm{B}$ \\
\hline Bal. & 3.63 & 3.99 & 11.98 & 1.81 & 8.7 & 3.83 & 5.09 & 0.005 & 0.069 & 0.0025 \\
\hline
\end{tabular}

Table 2 Composition of the ceramic materials for shell molds (wt\%)

\begin{tabular}{lllll}
\hline Material & $\mathrm{Al}_{2} \mathrm{O}_{3}$ & $\mathrm{SiO}_{2}$ & $\mathrm{Fe}_{2} \mathrm{O}_{3}$ & $\mathrm{Na}_{2} \mathrm{O}+\mathrm{K}_{2} \mathrm{O}$ \\
\hline White alumina & 99.13 & 0.08 & 0.07 & 0.4 \\
EC95 & 94.90 & 3.81 & 0.06 & 0.2 \\
\hline
\end{tabular}

The undercoolability of an alloy refers to the capability of an alloy melt remaining in the liquid state without nucleation when the temperature drops below the melting point. An alloy undercoolability represents the alloy's resistance to the SG formation during the directional solidification of SX castings.

In the present work, turbine blades of SX superalloy PWA1483 were produced in directional solidification experiments to study the SX castability of the used alloy. The critical nucleation undercooling of the alloy was measured during isothermal heating and cooling processes. Based on the results of the SX solidification and undercooling experiments, the relationship between the undercoolability and the SX castability of the used alloy was analyzed.

\section{Materials and Methods}

\subsection{Materials}

The nominal chemical composition of PWA1483 superalloy produced by Cannon-Muskegon is listed in Table 1. The ceramic molds used in the present investigation were produced in-house. The solid in slurry and the sand of the first layer of the ceramic molds are white alumina. The backup layer of the ceramic molds is EC95. The composition of these materials is listed in Table 2.

\subsection{Directional Solidification Experiments}

\subsubsection{Mold Preparation}

Real (Fig. 1a) and dummy blades (Fig. 1b) were comparatively studied in this work. A wax mold cluster having four real blades and two dummy blades assembled around a central rod was designed, as shown in Fig. 1c. The grain selection method was used to produce SX blades. The ceramic shell mold, as shown in Fig. 1d, was produced in a standard investment casting procedure. The wax mold cluster was dipped into water-based ceramic slurries and then stuccoed by different sizes of white alumina (first layer) and EC95 (backup layer) sands. The dipping and stuccoing operations (a)

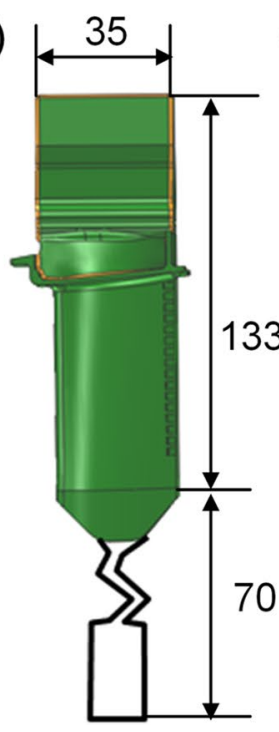

(b)

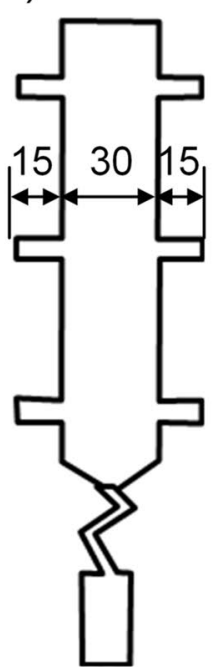

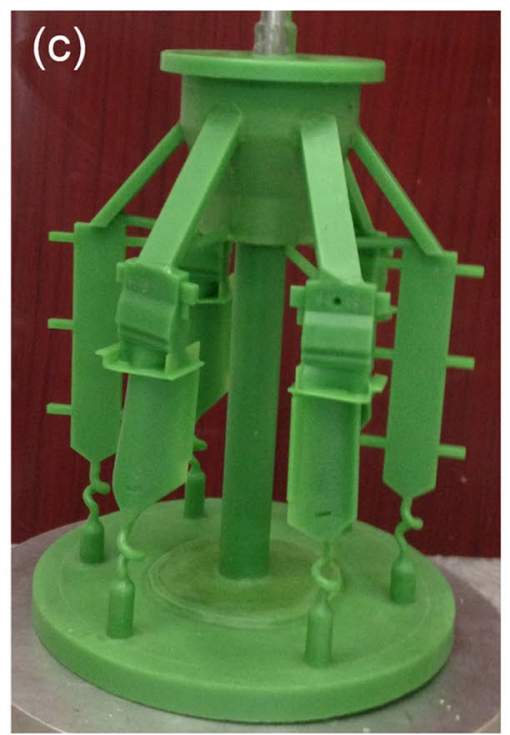

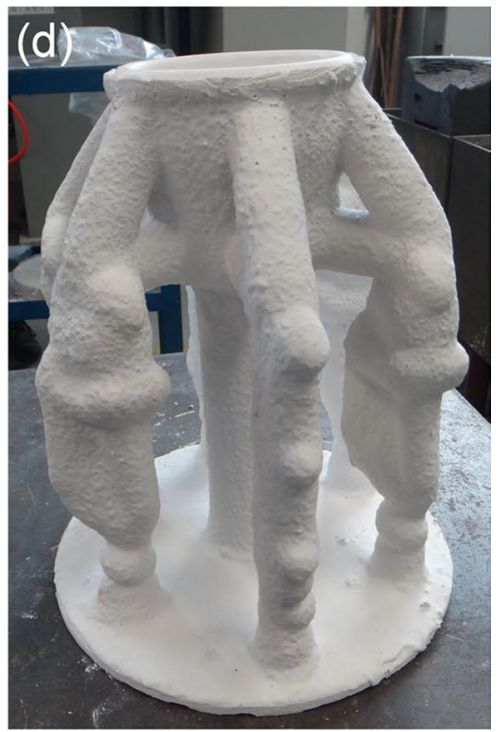

Fig. 1 Geometry of real $\mathbf{a}$ and dummy blades $\mathbf{b}$, as well as wax cluster cshell mold $\mathbf{d}$ 
were repeated until the wall thickness of the shell mold cluster reached about $8 \mathrm{~mm}$. After drying, the mold cluster was dewaxed in a steam autoclave. Then, the mold was presintered at a low temperature to remove the residual wax and then sintered at higher temperatures to strengthen the mold.

\subsubsection{Casting and Macrostructure Examination}

In the casting process, the shell mold was placed on a watercooled chill plate inside of a Bridgman furnace made by ALD Vacuum Technologies Inc. The mold was then raised into a cylindrical graphite heater. A vacuum of about $3 \times 10^{-4}$ mbar was maintained prior to preheat the mold to $1500{ }^{\circ} \mathrm{C}$. Pouring temperature was set to be $1500{ }^{\circ} \mathrm{C}$. Varied withdrawal rates of 1 and $3 \mathrm{~mm} \mathrm{~min}^{-1}$ were applied during the solidification of the platforms and the rest parts of the blades, respectively. After the withdrawal process, the mold was cooled in the cooling zone of the furnace. When the temperature of the furnace drops down below $300{ }^{\circ} \mathrm{C}$, the vacuum was released and the casting mold was removed. The entire casting cluster was then knocked out of the shell mold. The blades were then sandblasted to remove ceramic debris attached on the blade surfaces. In the end, the blades were etched using a $50 \% \mathrm{H}_{2} \mathrm{O}_{2}+50 \% \mathrm{HCl}$ etchant to reveal the macrostructure.

\subsection{Undercooling Experiments}

The undercoolability of an alloy is its ability to be cooled to a temperature below the melting point $\left(T_{\mathrm{L}}\right)$ without the onset of solidification. It can be determined as the statistic average of the critical nucleation undercooling $\left(\Delta T_{\mathrm{N}}\right)$ measured during an amount of experiments. In order to determine the undercoolability of PWA1483, a shell mold cluster was designed to measure the undercooling, as shown in Fig. 2. Small spherical samples of $12 \mathrm{~mm}$ diameter were used in the experiment. A shell mold having four spherical samples was produced by the same way as that applied in the SX blade casting experiment. To measure the temperature development in the samples during the process, the thermocouples of type B (Pt-30\% Rh/Pt-6\% Rh) were inserted into the center of the spherical samples of the mold. Before the experiment, the mold was placed in a vacuum furnace and the sprue was filled with PWA1483 superalloy with a weight of about $200 \mathrm{~g}$.

Under vacuum condition, the furnace was heated to $1500{ }^{\circ} \mathrm{C}$. During the heating process, the PWA1483 superalloy inside of the sprue was melted and filled into the spherical cavities. After 10 min homogenizing time, the heater was switched off to cool down the melt until it solidified. When the temperature of the furnace dropped to $1200{ }^{\circ} \mathrm{C}$, the heater was switched on again to start a new melting-solidification cycle in order to obtain more experimental data.

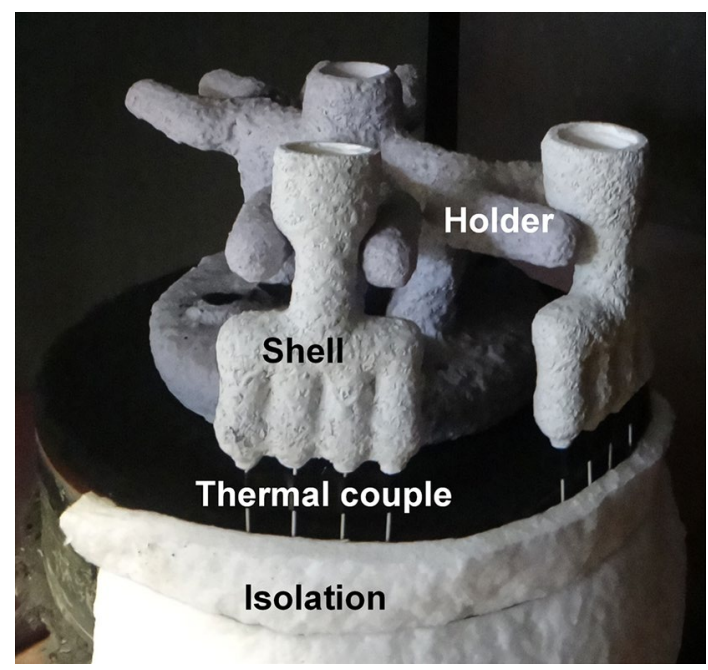

Fig. 2 Installation of shell mold with thermocouples

During each melting-solidification cycle, the temperature evolutions of the samples were recorded and used to calculate the critical undercooling of the PWA1483 superalloy.

\section{Results and Discussion}

\subsection{Macrostructure of Blades}

Figures 3 and 4 show the macrostructure of the real blades and dummy blades cast by using PWA1483 superalloy. It can be seen that no stray grain was detected in those two kinds of blades. Both of them have a complete SX structure. The result tells that the PWA1483 superalloy has good SX castability under the applied directional solidification processing parameters.

\subsection{Determination of the Undercooling}

Figure 5 shows the temperature evolution of the heater and the four spherical samples (07\#, 10\#, 11\# and 12\#) during the three melting-solidification cycle processes. It can be seen that the differences between the temperature curves among them are small. They almost overlap each other.

Figure 6 shows the cooling and heating curves in the first cycle only. It can be seen that during the cooling, the temperatures of the four spherical samples all have a small jump as the temperature drops to around $1300{ }^{\circ} \mathrm{C}$, indicating the release of latent heat due to the initial solidification of the alloy melt. The lowest temperature before the jump is the nucleation temperature $\left(T_{\mathrm{N}}\right)$ of the melt. Due to the characteristics of the nucleation, the measured nucleation temperatures for different samples may vary. Based on the cooling section in Fig. 6, the cooling rate can be estimated as: 

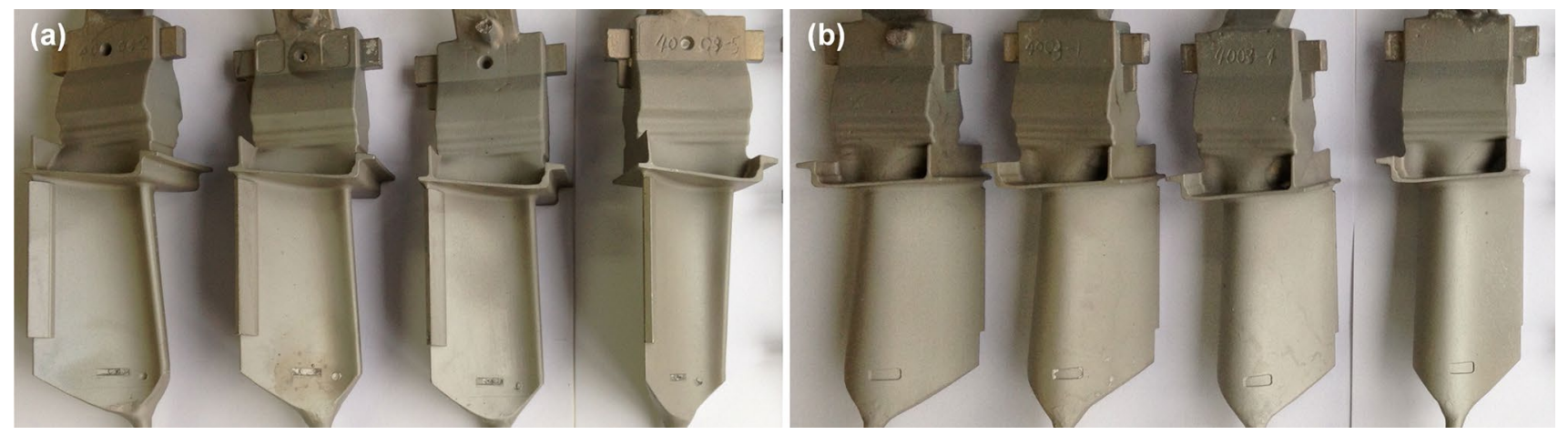

Fig. 3 Macro-etched real blades without stray grains: a concave side, $\mathbf{b}$ convex side
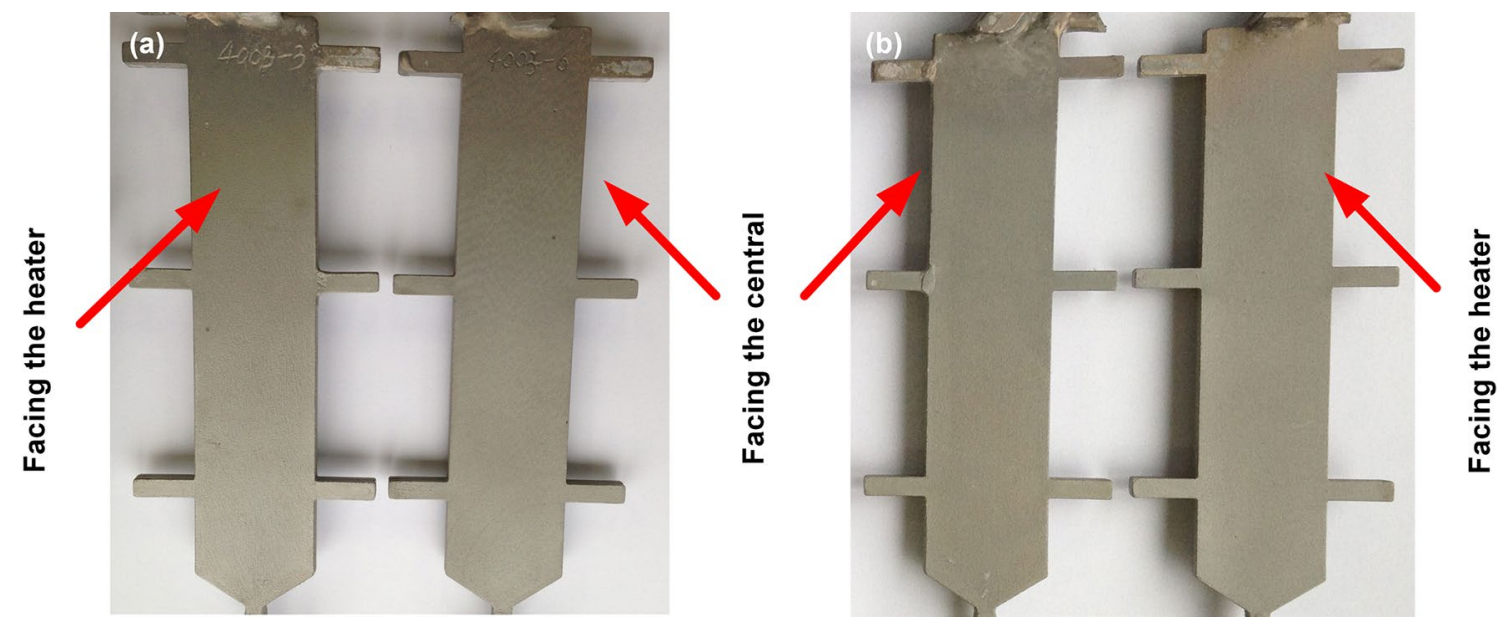

Fig. 4 Macro-etched dummy blades without stray grains: a front, b reverse side

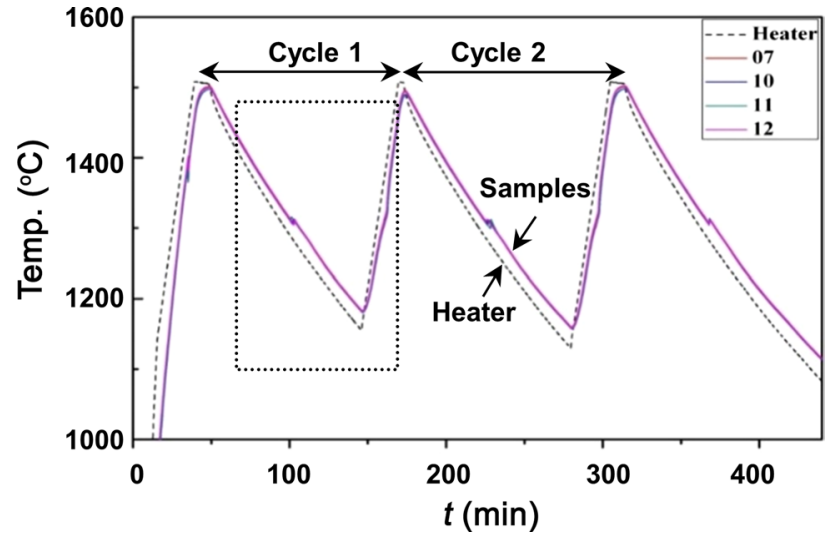

Fig. 5 Temperature evolution of the heater and four spherical samples during the melting-solidification process

$T^{\prime}=\frac{1455-1200\left({ }^{\circ} \mathrm{C}\right)}{140-60(\min )}=3.2\left({ }^{\circ} \mathrm{C} / \mathrm{min}\right)$.

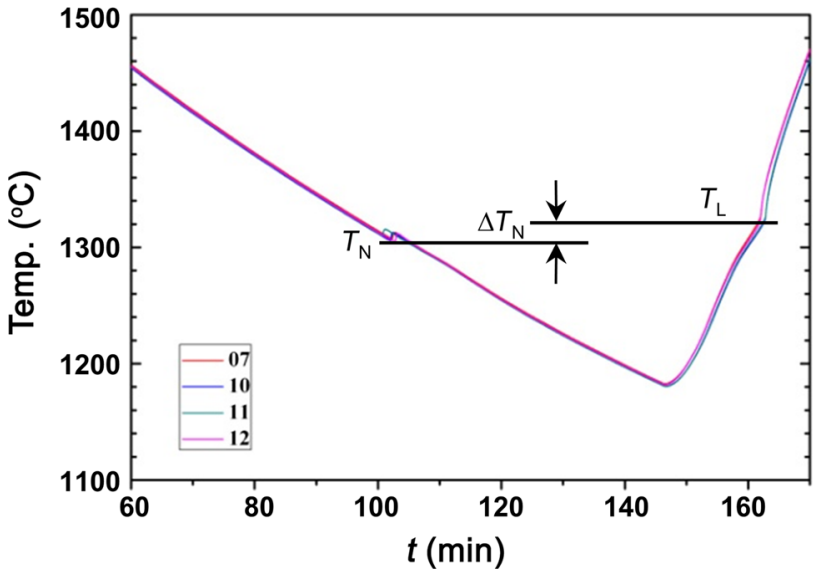

Fig. 6 Temperature curves of the samples measured in the first cycle

Our previous study shows that the thermal gradient $G$ in directional solidification experiments is around $3.1{ }^{\circ} \mathrm{C}$ 
$\mathrm{mm}^{-1}$. The withdrawal rate of $1 \mathrm{~mm} \mathrm{~min}^{-1}$ was used to pass the platform of the blades. The cooling rate $\left(T^{\prime}=G V\right)$ can be calculated as $3.1{ }^{\circ} \mathrm{C} \mathrm{min}^{-1}$, which is close to the measured cooling rate based on the cooling curve in Fig. 6. It suggests that the designed undercooling experiment can represent the extreme situation of the undercooling phenomenon at the extremities of the blade platform during the solidification.

The cooling curve in Fig. 6 changed into a heating curve after around $140 \mathrm{~min}$. After a brief transition, the temperature of the samples increases sharply at first and then slows down. Around $1330^{\circ} \mathrm{C}$, the slope of the temperature curve suddenly increases, which indicates that the alloy left the mushy zone became all liquid. This transition point can be considered as the melting point of the alloy $\left(T_{\mathrm{L}}\right)$. The difference between the $T_{\mathrm{L}}$ and $T_{\mathrm{N}}\left(\Delta T_{\mathrm{N}}=T_{\mathrm{L}}-T_{\mathrm{N}}\right)$ is the critical nucleation undercooling of the samples during the first experimental cycle. The averaged measured undercooling of PWA1483 superalloy is defined as the critical nucleation undercooling of this alloy.

Table 3 summarizes the measurement results of the samples during the two applied melting-solidification cycles. The measurement results had a good consistency. The average nucleation temperatures of four samples in the two cycles are $1306.5{ }^{\circ} \mathrm{C}, 1306{ }^{\circ} \mathrm{C}, 1305.5{ }^{\circ} \mathrm{C}$ and $1307{ }^{\circ} \mathrm{C}$, respectively. The average melting point in the two cycles is $1327.5^{\circ} \mathrm{C}$ and $1326.25^{\circ} \mathrm{C}$, respectively. The average critical nucleation undercooling can be calculated as $21^{\circ} \mathrm{C}$. It can be seen that under the current experimental conditions, the solidification characteristics of the alloy did not change in each experimental cycle. The results suggest that the alloy exhibits analogous solidification behavior although it was remolten and solidified repeatedly. And the alloy as well as the mold has good chemical stability.

Based on the average melting point and nucleation temperature, the average critical nucleation undercooling can be calculated as $21^{\circ} \mathrm{C}$. This value is rather large, indicating that the PWA1483 superalloy has a relatively high undercoolability in comparison with some superalloys, such as IN939 [14].

During the directional solidification process, the alloy melt at the outer extremities of the blade platform cooled rapidly and the local undercooling is normally higher than $10{ }^{\circ} \mathrm{C}$, due to the thin shell and a faster heat loss [15]. If the local undercooling does not exceed the undercoolability (the critical undercooling) of the PWA1483 superalloy, the melt will remain in a liquid state until the SX growth of the blade body extends laterally into the platform. This epitaxial growth into the local undercooled melt ensures the continuity and uniformity of SX growth and avoids the occurrence of SGs [5-7].

The nucleation of an undercooled alloy melt is spontaneous and may not occur under a fixed undercooling each time. However, for an alloy under a certain solidification condition, the average nucleation undercooling and its distribution range can be measured. Table 3 shows that the average critical nucleation undercooling of PWA1483 superalloy is about $21{ }^{\circ} \mathrm{C}$, and the exact measurement values of the different samples are not the same which ranged between 17 and $24{ }^{\circ} \mathrm{C}$. The conditions of this experiment are similar to the SX directional solidification experiments in different conditions, such as the material of the shell mold, the vacuum furnace and furnace atmosphere. As mentioned above, the cooling rate of the alloy melt is very similar as well. Therefore, the nucleation and crystallization behavior of the new grain examined in this experiment can represent the occurrence of the stray grain during the solidification of SX blades. In the first part of this paper (the SX solidification experiment), no SGs formed in the platforms of the real blades and at the convex platforms of the dummy blades. The results indicate that the undercooling of the alloy melt in these sensitive positions did not exceed the undercoolability of the PWA1483 superalloy before the SX grain grew into these regions, and the nucleation and growth of the new grains did not occur. It suggests that the PWA1483 superalloy has good resistance to the SG formation for SX blades manufacturing.

\section{Conclusion}

The PWA1483 superalloy was used to cast SX blades in the vacuum Bridgman furnace using an in-house designed ceramic shell mold. The results showed that all the blades were casted in SX form, and there were no SGs formed, even in the sensitive areas such as the platform of the blade. Through undercooling experiments, the melting point $\left(T_{\mathrm{L}}\right)$ of PWA1483 superalloy was determined to be around $1327{ }^{\circ} \mathrm{C}$ and the average nucleation temperature $\left(T_{\mathrm{N}}\right)$ in the used shell mold is about $1306{ }^{\circ} \mathrm{C}$. The average critical nucleation undercooling (undercoolability) was calculated as
Table 3 Summary of the temperature data $\left({ }^{\circ} \mathrm{C}\right)$ measured during undercooling experiment

\begin{tabular}{|c|c|c|c|c|c|c|c|c|c|c|c|}
\hline \multirow[t]{2}{*}{ Thermal couple } & \multicolumn{5}{|c|}{ Cycle 1} & \multicolumn{5}{|c|}{ Cycle 2} & \multirow[t]{2}{*}{ Average } \\
\hline & 07\# & $10 \#$ & $11 \#$ & $12 \#$ & Average & 07\# & $10 \#$ & $11 \#$ & $12 \#$ & Average & \\
\hline$T_{\mathrm{N}}$ & 1307 & 1306 & 1310 & 1305 & 1307 & 1306 & 1306 & 1301 & 1309 & 1306 & 1306 \\
\hline$T_{\mathrm{L}}$ & 1330 & 1326 & 1327 & 1327 & 1328 & 1329 & 1325 & 1325 & 1326 & 1326 & 1327 \\
\hline$\Delta T_{\mathrm{N}}$ & 23 & 20 & 17 & 22 & 21 & 23 & 19 & 24 & 17 & 21 & 21 \\
\hline
\end{tabular}


$\Delta T_{\mathrm{N}}=T_{\mathrm{L}}-T_{\mathrm{N}}=21^{\circ} \mathrm{C}$. This value is large enough so that the nuclei of new grain at the outer corner of the blade will not form easily, indicating that the PWA1483 alloy has a good SX casting ability.

Acknowledgements This work was financially supported by the Shenzhen Peacock Plan (Grant No. 20150128085205453), the Program for Guangdong Introducing Innovative and Entrepreneurial Teams (Grant No. 607264877417), the National Natural Science Foundation of China (Grant No. 51505457), the National Science and Technology Major Project (Grant No. 2017-Vll-0008), the Key Research and Development Program of Shaanxi Province (Grant No. 2018ZDXMGY-059) and the National Science and Technology Major Project (No. 2017ZX04014001)

\section{References}

[1] R. Schafrik, Acta Metall. Sin. (Engl. Lett.) 18, 561 (2005)

[2] R. Reed, The Superalloys: Fundamentals and Applications (Cambridge University Press, London, 2006), pp. 130-131

[3] U. Paul, P. Sahm, D. Goldschmidt, Mater. Sci. Eng. A 173, 49 (1993)
[4] W. Xuan, Z. Ren, C. Li, W. Ren, C. Chen, IOP Conf. Series Mater. Sci. Eng. 27, 012035 (2011)

[5] X. Zhang, Y. Zhou, T. Jin, X. Sun, Acta Metall. Sin. 48, 1229 (2012). (in Chinese)

[6] X. Meng, J. Li, S. Zhu, H. Du, Z. Yuan, J. Wang, T. Jin, X. Sun, Z. Hu, Metall. Mater. Trans. A 45, 1230 (2014)

[7] W. Xuan, Z. Ren, C. Li, Metall. Metall. Mater. Trans. A 46, 1461 (2015)

[8] W. Xuan, L. Huan, C. Li, Z. Ren, Y. Zhong, X. Li, G. Cao, Metall. Mater. Trans. B 47, 828 (2016)

[9] M. Meyer ter Vehn, D. Dedecke, U. Paul, P. Sahm, in Proceedings of the Superalloys 1996, ed. by R. Kissingger, D. Deye, D. Anton, A. Cetel, M. Nathal, T. Pollock, D. Woodford (TMS, Warrendale, 1996), p. 471

[10] D. Ma, A. Bührig-Polaczek, Metall. Mater. Trans. B 40, 738 (2009)

[11] D. Ma, A. Bührig-Polaczek, Int. J. Cast Met. Res. 22, 422 (2009)

[12] S. Bogner, E. Ivanova, M. Müller, F. Wang, D. Ma, A. BührigPolaczek, Metals 5, 1971 (2015)

[13] Y. Li, L. Liu, D. Sun, Q. Yue, T. Huang, B. Gan, J. Zhang, H. Fu, J. Alloys Compd. 773, 432 (2019)

[14] D. Ma, Q. Wu, A. Bührig-Polaczek, Adv. Mater. Res. 278, 417 (2011)

[15] D. Ma, Q. Wu, A. Bührig-Polaczek, IOP Conf. Series Mater. Sci. Eng. 27, 012037 (2011) 